Article

\title{
Repair Bond Strength of a Resin Composite to Plasma-Treated or UV-Irradiated CAD/CAM Ceramic Surface
}

\author{
Atsushi Kameyama ${ }^{1,2}, *(\mathbb{D})$, Akiko Haruyama ${ }^{3}\left[{ }^{(0)}\right.$, Akihiro Tanaka ${ }^{4}$, Akio Noro ${ }^{2}$, \\ Toshiyuki Takahashi ${ }^{2}$, Masao Yoshinari ${ }^{5}$, Masahiro Furusawa ${ }^{6}$ and Shuichiro Yamashita 4 \\ 1 Department of Operative Dentistry, Cariology and Pulp Biology (Chiba Campus), Tokyo Dental College, \\ Chiba 261-8502, Japan \\ 2 Division of General Dentistry, Tokyo Dental College Chiba Dental Center, Chiba 261-8502, Japan; \\ noro@tdc.ac.jp (A.N.); totakaha@tdc.ac.jp (T.T.) \\ 3 Department of Operative Dentistry, Cariology and Pulp Biology (Suidobashi Campus), \\ Tokyo Dental College, Tokyo 101-0061, Japan; akiharu@tdc.ac.jp \\ 4 Department of Removable Partial Prosthodontics, Tokyo Dental College, Tokyo 101-0061, Japan; \\ tanakaakihiro@tdc.ac.jp (A.T.); syamashita@tdc.ac.jp (S.Y.) \\ $5 \quad$ Oral Health Science Center, Tokyo Dental College, Tokyo 101-0061, Japan; yosinari@tdc.ac.jp \\ 6 Department of Endodontics, Tokyo Dental College, Tokyo 101-0061, Japan; mfurusaw@tdc.ac.jp \\ * Correspondence: kameyama@tdc.ac.jp; Tel.: +81-43-270-3941
}

Received: 6 May 2018; Accepted: 24 June 2018; Published: 28 June 2018

\begin{abstract}
The aim of this study was to investigate whether atmospheric-pressure plasma (APP) or ultraviolet (UV) irradiation could alter the hydrophilicity of a computer-aided design/computer-aided manufacturing (CAD/CAM) glass ceramic surface, and thereby enhance the repair bond strength between the ceramic and a resin composite. Forty-eight leucite-reinforced glass ceramic discs were treated with $40 \%$ phosphoric acid and randomly assigned into one of six groups: Group 1, control; Group 2, treated with a mixture of Clearfil SE Bond primer (SEP) and Clearfil Porcelain Bond Activator (PBA); Group 3, subjected to APP irradiation for 10 s; Group 4, subjected to UV irradiation for $60 \mathrm{~min}$; Group 5, APP irradiation followed by SEP/PBA; and Group 6, UV irradiation followed by SEP/PBA. After treatment, discs were bonded with resin composite using Clearfil SE Bond and stored in water at $37^{\circ} \mathrm{C}$ for 1 week. We then tested how these treatments affected the microtensile bond strength ( $\mu \mathrm{TBS}$ ) and measured changes in the water contact angle (CA). Samples from Group 2 showed the highest $\mu$ TBS $(44.3 \pm 6.0 \mathrm{MPa})$ and CA $\left(33.8 \pm 2.3^{\circ}\right)$, with no significant differences measured between Groups 1,3 , and $4(p<0.05)$. Furthermore, the additional treatments of APP or UV before SEP/PBA had no effect (Group 5, $p=0.229$ ) or a reduced effect (Group 6, $p=0.006$ ), respectively, on $\mu$ TBS. Overall, APP or UV irradiation before SEP/PBA treatment did not enhance the repair bond strength.
\end{abstract}

Keywords: atmospheric-pressure plasma; ultraviolet; CAD/CAM; ceramic repair; microtensile bond strength

\section{Introduction}

There has been a gradual increase in the demand for tooth-colored indirect restorations using computer-aided design/computer-aided manufacturing (CAD/CAM) ceramic-based materials in clinical dentistry. These materials have excellent resistance to wear, maintain their toothlike appearance, are chemically stable, and have low long-term plaque extension rates [1,2]. However, patient-related parafunctional habits are frequently reported as a major cause of marginal chipping, body fracture, 
and crevice formation at the margin, due to frictional wear of the luting cement [3]. Although replacement of the entire restoration is needed after ceramic fracture, intraoral repair is suitable, inexpensive, and less invasive in some situations, especially when the chipped area is small or the marginal crevice is shallow [4].

Ceramic restorations can be repaired with surface conditioning methods or intraoral adhesive promoters. Hydrofluoric acid etching and silane coating can enhance the bond strength of resin composites to glass ceramics $[5,6]$. However, contact with hydrofluoric acid should be avoided because of its adverse effect on the bond strength of the composite to enamel and dentin [7,8]. Clinically, selective intraoral application of hydrofluoric acid to the ceramic is not easy, and therefore, contact with enamel and dentin is sometimes unavoidable. In Japan, hydrofluoric acid cannot be used for intraoral repair because of its hazardous effects [9]; in 1982, a 3-year-old Japanese girl died of acute drug intoxication because a dentist mistook hydrofluoric acid for sodium fluoride [10]. This has led to the use of phosphoric acid to etch before the silane coating is applied in Japan.

Recent studies have demonstrated that exposure to atmospheric-pressure plasma (APP) or ultraviolet light (UV) can modify the physicochemical properties of some dental materials and enhance wettability [11,12]. It would also be reasonable to hypothesize that using APP and UV to alter the surface texture of the adhered ceramic when restoring ceramic might provide an alternative solution to enhance the repair bond strength of resin composites to the ceramic. However, they are still ambiguous to improve the bonding performance of dental restorative materials.

The objectives of this study were to investigate whether APP or UV irradiation could alter the hydrophilicity of CAD/CAM glass ceramic surfaces, and determine if this alteration could enhance the repair bond strength between a resin composite and ceramic. The null hypotheses were, therefore, as follows (1) exposing CAD/CAM glass ceramic to APP or UV would not affect the wettability, and (2) pre-treating CAD/CAM glass ceramic with APP or UV would not further improve the repair bond strengths.

\section{Materials and Methods}

\subsection{Group Setting}

Leucite-reinforced CAD/CAM glass ceramic blocks (IPS Empress CAD for CEREC and InLab, HT / A2 I12, Ivoclar Vivadent, Schaan, Liechtenstein) were cut into 48 ceramic discs of $6 \mathrm{~mm}$ thickness using a low-speed water-cooled diamond saw (Isomet, Buehler, Lake Bluff, IL, USA). The cut surface was then sequentially abraded under a stream of water with SiC paper from \#220 up to \#600 (Buehler, Lake Bluff, IL, USA) to prepare a uniform and flat surface. After ultrasonically cleaning (ASU-6M, AS ONE, Osaka, Japan) in acetone for $10 \mathrm{~min}$ and thoroughly drying using compressed air, each disc was treated for $5 \mathrm{~s}$ with $40 \%$ phosphoric acid (K-etchant GEL, Kuraray Noritake Dental, Tokyo, Japan) (See Table 1). All specimens $(n=48)$ were randomly assigned into one of 6 groups $(n=8)$ :

- Group 1 (control): No additional treatment.

- Group 2 (SEP/PBA): Coated with a 1:1 mixture of Clearfil SE Bond primer (Kuraray Noritake Dental) and Clearfil Porcelain Bond Activator (Kuraray Noritake Dental) (SEP/PBA) followed by compressed air-drying.

- Group 3 (APP): Irradiated with APP (NJZ-2820, Nagano Japan Radio, Nagano, Japan) for $10 \mathrm{~s}$ (150 W, spot diameter $4 \mathrm{~mm}$, gas flow rate $6 \mathrm{~L} / \mathrm{min}$ ).

- Group 4 (UV): Irradiated with UV light (BioForce Nanosciences, Stockholm, Sweden) for $60 \mathrm{~min}$, with a total power of $19 \mathrm{~mW} / \mathrm{cm}^{2}$, and excitation wavelengths of $185 \mathrm{~nm}$ and $254 \mathrm{~nm}$, corresponding to ultraviolet $\mathrm{C}$ (UV-C), and $365 \mathrm{~nm}$ corresponding to ultraviolet A (UV-A).

- Group 5 (APP + SEP/PBA): Irradiated with APP for 10 s, coated with SEP/PBA, and then dried by compressed air.

- Group $6(\mathrm{UV}+\mathrm{SEP} / \mathrm{PBA})$ : Ceramic surface was irradiated by UV light for 60 min, coated with $\mathrm{SEP} / \mathrm{PBA}$, and then dried by compressed air. 
From these groups, five discs were taken for the wettability measurement, and the remaining three discs were for $\mu$ TBS.

Table 1. Materials used in this study.

\begin{tabular}{cccc}
\hline Product & Manufacturer & Batch No. & Principal Ingredients \\
\hline $\begin{array}{c}\text { IPS Empress CAD for CEREC } \\
\text { and InLab (HT / A2 I12) }\end{array}$ & $\begin{array}{c}\text { Ivoclar Vivadent, } \\
\text { Schaan, Liechtenstein }\end{array}$ & S28661 & $\begin{array}{c}\text { Leucite reinforced CAD/CAM glass ceramic } \\
\text { (Silicon dioxide, aluminum oxide, potassium oxide, } \\
\text { sodium oxide, pigments) }\end{array}$ \\
\hline K-etchant GEL & $\begin{array}{c}\text { Kuraray Noritake } \\
\text { Dental, Tokyo, Japan }\end{array}$ & 1N0018 & 40\% phosphoric acid \\
\hline $\begin{array}{c}\text { Clearfil Porcelain } \\
\text { Bond Activator }\end{array}$ & $\begin{array}{c}\text { Kuraray Noritake } \\
\text { Dental, Tokyo, Japan }\end{array}$ & 260010 & 3-MPS \\
Clearfil SE Bond & $\begin{array}{c}\text { Kuraray Noritake } \\
\text { Dental, Osaka, Japan }\end{array}$ & $\begin{array}{c}\text { Primer: 1E0067 } \\
\text { Bond: 1U0111 }\end{array}$ & $\begin{array}{c}\text { Primer: HEMA, 10-MDP, hydrophilic dimethacrylate, } \\
\text { water, photoinitiator (CQ, DEPT) } \\
\text { Bond: Bis-GMA, 10-MDP, HEMA, hydrophobic } \\
\text { dimethacrylate, silanized colloidal silica, photoinitiator }\end{array}$ \\
\hline $\begin{array}{c}\text { Herculite XRV } \\
\text { (Dentine A2) }\end{array}$ & $\begin{array}{c}\text { Kerr, Orange, } \\
\text { CA, USA }\end{array}$ & 5109591 & Bis-GMA, TEGDMA, CQ, filler \\
\hline
\end{tabular}

Notes: Bis-GMA, bisphenol-glycidyl methacrylate; HEMA, 2-hydroxyethylmethacrylate; 10-MDP, 10-methacryloyloxydecyl dihydrogen phosphate; 3-MPS, bisphenol A polyethoxy dimethacrylate 3-methacryloyloxypropyltrimethoxy silane; TEGDMA, triethylene glycol dimethacrylate; UDMA, urethane dimethacrylate; CQ, DL-camphorquinone; DEPT, $N, N$-diethanol- $p$-toluidine.

\subsection{Measurement of Wettability against Water}

The wettability of each sample was determined by contact angle (CA) measurements using double-distilled water and a CA meter (Phoenix-Alpha, Meiwafosis, Tokyo, Japan). Measurements were made $3 \mathrm{~s}$ after application of the droplet at room temperature $\left(23^{\circ} \mathrm{C}\right)$. The volume of the drop was maintained at $4 \mu \mathrm{L}[11,12]$. The images were recorded and the CA was measured with software (Surfaceware 7; SEO, Suwon, Korea) $(n=5)$.

\subsection{Microtensile Bond Strength ( $\mu$ TBS) Testing}

A schematic illustration of specimen preparation is shown in Figure 1. The treated surfaces in each group were coated with Clearfil SE Bond bonding agent, and then light-cured for $40 \mathrm{~s}$ using an LED light-curing unit (G-Light Prima, GC, Tokyo, Japan). The surface was then built up incrementally with a resin composite (Herculite XRV, Kerr, Orange, CA, USA; Shade Dentine A2) over six steps to a height of approximately $6 \mathrm{~mm}$. The sample was light-cured for $60 \mathrm{~s}$ at each increment. Light intensity was controlled using a hand-held dental radiometer (Bluephase meter; Ivoclar Vivadent, Schaan, Liechtenstein) to ensure a light output of at least $1500 \mathrm{~mW} / \mathrm{cm}^{2}$ [13].

Specimens were stored in distilled water at $37^{\circ} \mathrm{C}$ for 1 week, and then serially sectioned perpendicularly to the adhesive interface into about $1 \mathrm{~mm}^{2}$ stick-shaped microspecimens with a $300 \mu \mathrm{m}$ diamond cut-off wheel (Isomet, Buehler, Lake Bluff, IL, USA). Twelve of the obtained microspecimens were selected form the center of each specimen, and visually examined each specimen using 2.8× magnification Galilean dental loupes (Rudy Project Rydon, Orascoptic, Middleton, WI, USA) with integrated LED light source (ZEON Discovery, Orascoptic, Middleton, WI, USA). The microspecimens with obvious defects, e.g., voids and gaps within the built-up composite, were eliminated before bond testing. Specimen strength was tested by attaching each stick to a microtensile jig using cyanoacrylate glue (Model Repair II Blue, Dentsply-Sankin, Ohtawara, Japan). The sticks were then submitted to a tensile load using a Micro Tensile Tester (Bisco Inc., Schaumburg, IL, USA) at $1.0 \mathrm{~mm} / \mathrm{min}$ crosshead speed until failure. The width and thickness of each specimen was measured to the nearest $0.01 \mathrm{~mm}$ using a digital caliper (CD-15 CPX, Mitutoyo, Tokyo, Japan), which was used to determine the microtensile bond strength ( $\mu \mathrm{TBS}, \mathrm{MPa}$ ) by dividing the recorded force $(\mathrm{N})$ at the time of fracture by the bond area $\left(\mathrm{mm}^{2}\right)$. If a specimen failed before proper testing, a bond strength of $0 \mathrm{MPa}$ was used for statistical analyses [14,15]. The actual number of pre-testing failures was explicitly noted, as well. 
(a)

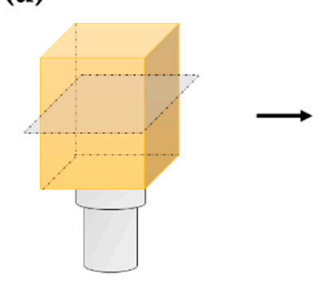

(b)

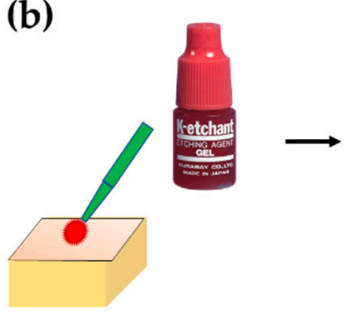

(e) (c)

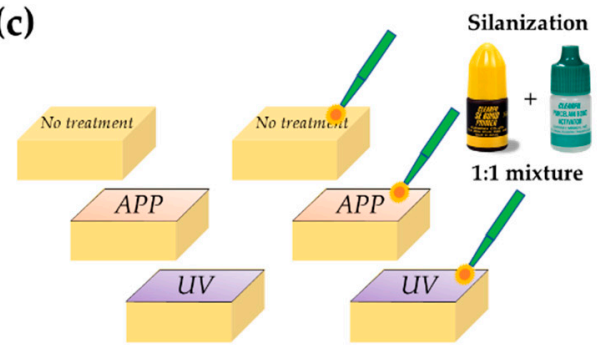

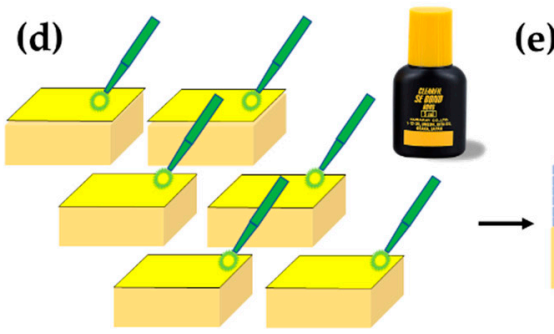

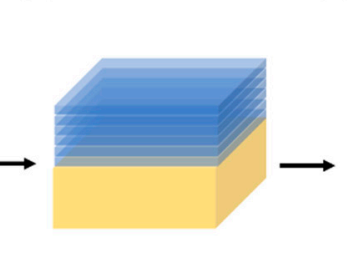

(f)

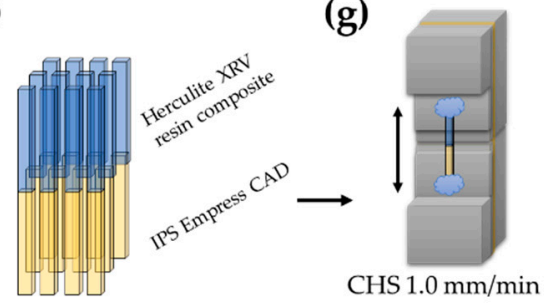

Figure 1. Summary diagram of microtensile bond strength ( $\mu$ TBS) testing. (a) IPS Empress CAD was cut into 6 mm-thick slabs; (b) After ultrasonically cleaning, each slab was treated with K-etchant GEL; (c) Each specimen was assigned into 6 groups; (d) The treated surface was coated with Clearfil SE Bond and light-cured and (e) built up incrementally with Herculite XRV; (f) Resin-ceramic microspecimens $(1 \mathrm{~mm} \times 1 \mathrm{~mm})$ were cut with diamond saw and $(\mathrm{g})$ they were stressed until failure.

\subsection{Statistical Analysis}

Data were analyzed using a one-way analysis of variance (ANOVA) with the three surface modification methods and silanization as primary parameters. According to assumption of homogeneity of variance, Tukey's HSD and Games-Howell tests were used for water CA and $\mu$ TBS values, respectively. The critical value was 0.05 . All statistical analyses were carried out using the SPSS statistical software (IBM SPSS 18; SPSS Inc., Chicago, IL, USA).

\section{Results}

\subsection{Water $C A$}

Figure 2 shows a cross-sectional view of a water droplet on each specimen after surface treatment and the CA. The control specimen (treated by phosphoric acid) showed the lowest CA $\left(7.2 \pm 1.1^{\circ}\right)$, and no significant difference was found between control and UV-treated samples $\left(7.6 \pm 1.9^{\circ}, p=0.998\right)$. The CA of the APP-treated group $\left(10.0 \pm 1.2^{\circ}\right)$ was slightly higher than that of the control group $(p=0.041)$. The mixture of SEP and PBA application after phosphoric acid treatment enhanced the CA $\left(33.8 \pm 2.3^{\circ}, p=0.000\right)$; however, pretreatment with APP did not improve the wettability over $\mathrm{SEP} / \mathrm{PBA}$ treatment alone $(p=0.838)$. Intriguingly, UV irradiation before SEP/PBA treatment led to a significantly lower CA than SEP/PBA samples not subjected to UV pretreatment $(p=0.017)$.

\section{2. $\mu T B S$}

The mean $\mu$ TBS, standard deviation (SD), median, range, total number of specimens $(n)$, and number of pre-testing failures (PTF) per group are summarized in Table 2. There were 27 PTF for the control and UV groups, and 32 for the APP group. No significant differences were found among the control, APP, and UV groups $(p>0.05)$. No specimens failed in the groups that incorporated SEP/PBA. SEP/PBA treatment resulted in the highest $\mu$ TBS, but the additional treatment of APP before SEP/PBA had no effect on the $\mu \mathrm{TBS}(p=0.229)$, and UV pre-treatment before SEP/PBA reduced the $\mu$ TBS $(p=0.006)$. 

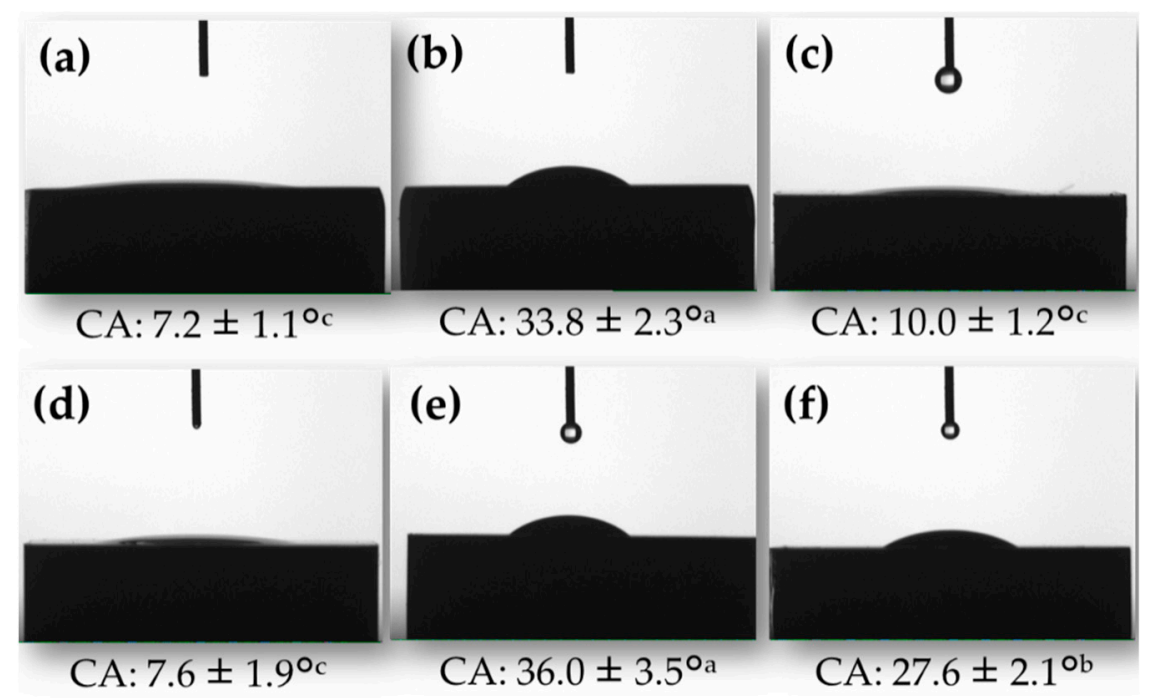

Figure 2. Representative cross-sectional images of a water droplet on glass ceramic surfaces: (a) control (only K-etchant); (b) SEP/PBA; (c) APP; (d) UV; (e) APP + SEP/PBA; and (f) UV + SEP/PBA. $\mathrm{CA}$ : contact angle (mean $\left.\pm \mathrm{SD},^{\circ}\right)$. Values with the same superscript letters showed no statistical significance $(p>0.05)$.

Table 2. Microtensile bond strength ( $\mu$ TBS) and number of pre-testing failure (PTF) in each group.

\begin{tabular}{ccccc}
\hline Group & Treatment & $\begin{array}{c}\boldsymbol{\mu} \text { TBS } \\
\text { (Mean } \pm \text { SD; MPa) }\end{array}$ & Median (Range) & PTF $/ \boldsymbol{n}$ \\
\hline 1 & Control (K-etchant) & $4.4 \pm 9.0^{\mathrm{c}}$ & $0.0(0.0-35.2)$ & $27 / 35$ \\
2 & SEP/PBA & $44.3 \pm 6.0^{\mathrm{a}}$ & $44.3(29.8-59.5)$ & $0 / 33$ \\
3 & $\mathrm{APP}$ & $1.6 \pm 5.4^{\mathrm{c}}$ & $0.0(0.0-21.5)$ & $32 / 35$ \\
4 & $\mathrm{UV}$ & $3.1 \pm 7.8^{\mathrm{c}}$ & $0.0(0.0-29.6)$ & $27 / 32$ \\
5 & $\mathrm{APP}+\mathrm{SEP} / \mathrm{PBA}$ & $40.8 \pm 6.2^{\mathrm{ab}}$ & $39.9(33.0-57.4)$ & $0 / 29$ \\
6 & $\mathrm{UV}+\mathrm{SEP} / \mathrm{PBA}$ & $35.5 \pm 12.1^{\mathrm{b}}$ & $38.5(16.0-53.1)$ & $0 / 33$ \\
\hline
\end{tabular}

Notes: SD, standard deviation; $n$, total number of bonded specimens; PTF, pre-testing failure; SEP/PBA, 1:1 mixture of Clearfil SE Bond primer and Clearfil Porcelain Bond Activator; APP, atmospheric-pressure plasma; UV, ultraviolet light. The same superscript letters indicate no statistically significant differences ( $p<0.05$; Games-Howell tests).

\section{Discussion}

CAD/CAM materials are now widely used in clinical dentistry. Several studies have reported the bonding performances of these materials to enamel and dentin $[15,16]$. However, no studies have evaluated the repair of CAD/CAM ceramic blocks or the related bonding efficacy. This study was therefore designed to evaluate whether APP or UV light exposure to leucite-reinforced CAD/CAM glass-ceramic could enhance the repair bond strength of the ceramic to a resin composite.

Clearfil SE Bond, the adhesive used in this study, is known for its excellent bonding performance and durability for both enamel and dentin $[17,18]$, and therefore can be regarded as the gold standard among dental adhesives. Its behavior has been described by the adhesion-decalcification model [19]; molecules of 10-MDP contained in Clearfil SE Bond are chemically bonded to calcium $\left(\mathrm{Ca}^{2+}\right)$ ions, the calcium-phosphate monomer salt was co-polymerized with the adhesive resin monomer and was limited to surface decalcification. Furthermore, this adhesive has a high polymerization rate [20], and the high mechanical performance of the polymer itself is caused by the high filler loading [21,22].

Hydrofluoric acid etching has been reported to partially dissolve silica-based ceramic surfaces [23]. In doing so, it promotes micromechanical retention between the ceramic surface and the adhesive resin, thereby increasing the bond strength $[7,24,25]$. Comparatively, treatment with phosphoric acid produces minimal etching of the surface [26]. As a result, phosphoric acid etching is usually performed 
only to clean the adhered surface. Here, we showed that almost-bonded specimens in the control group that were treated with phosphoric acid failed before bond testing. The CA on the control surface was very low, which confirms that phosphoric acid etching only cleans the surface and creates a "hydrophilic" state.

Wettability of a solid is generally considered necessary to bond to the liquid adhesive agent. A higher surface energy of an adherent increases the wettability between the adherent and the adhesive agent. This study found that treatment with the mixture of SEP and PBA reduced wettability, because CA of SEP/PBA-treated surface was significantly higher than non-treated control. However, SEP/PBA-treatment significantly increased the $\mu$ TBS value, despite that the wettability was reduced. Silane has been widely recommended as a way of maximizing the bonding of silica-based ceramic to resin, as the hydroxyl and organofunctional terminal groups of silane can bond with silica and resin, respectively. The results obtained in this study indicate that after drying, silane treatment presumably generates polysiloxane bonds $(\mathrm{Si}-\mathrm{O}-\mathrm{Si})_{n}$ to the silica in the ceramic and vinyl carbon-carbon double bonds $\left(-\mathrm{CH}=\mathrm{CH}_{2}\right)$ of silane molecules, which would turn the "hydrophilic" glass ceramic surface into a "hydrophobic" one $[27,28]$. We therefore suggest that the "hydrophobic" Clearfil SE Bond tightly adheres to the "hydrophobic" silanized ceramic surface. Furthermore, the acidic functional monomer 10-MDP contained in SEP might accelerate the hydrolysis of the silane coupling agent, form silanol groups ( $\mathrm{Si}-\mathrm{OH})$, and efficiently bind to ceramics by forming a siloxane structure [29].

Plasma is the fourth state of matter constituting $>99 \%$ of the universe, and is one of the new treatments currently being tested as a dental biomaterial for direct and indirect application in the dental cavity [30]. Plasma is a mixture of highly reactive particles, including electronically excited molecules, ionic and free radical species, and UV photons [31]. Since plasma treatment increases the wettability of the treated surface, it is expected to enhance the bonding performance between the dental adhesive and dental substrate. Several reports demonstrated that plasma treatment to zirconia enhanced the resin bond strength [32-34]. We first assumed that APP or UV treatment to the surface of leucite-reinforced CAD/CAM glass ceramic might also enhance the bonding efficiency, the same as zirconia, due to improving the wettability of the treated ceramic surface. The first null hypothesis that exposing CAD/CAM glass ceramic to APP or UV would not affect the wettability, was accepted. However, our results found that both APP and UV treatments to ceramic surface kept hydrophilicity the same as the phosphoric acid-treated control $(p>0.05)$. Similarly to our results, Han et al. [35] reported that the contact angles of deionized water to APP-treated feldspathic porcelain (VITABLOCS Mark II, lower than $10^{\circ}$ ) were lower than ground surface $\left(15.9 \pm 3.8^{\circ}\right)$.

Our results suggested that neither APP nor UV treatment can mimic the etching effects achieved by hydrofluoric acid in the clinical setting. Therefore, the second null hypothesis, that pre-treating CAD/CAM glass ceramic with APP or UV would not improve the repair bond strengths, was also accepted. Han et al. [35] also reported that the shear bond strength to APP-treated ceramic was lower than the ceramic treated with the gold-standard hydrofluoric acid-etching and silane coupling agent [24]. According to some XPS (X-ray Photoelectron Spectroscopy) study, APP-treated ceramic surface showed that the content of $\mathrm{C}-\mathrm{C}$ bonds decreased, suggesting that organic matter was removed. By contrast, the content of oxygen-containing polar groups increased $(\mathrm{C}-\mathrm{O}-\mathrm{C}$ and $\mathrm{O}=\mathrm{C}-\mathrm{O})$, suggesting that APP treatment enhanced the surface hydrophilicity $[32,35,36]$.

In the case of intraoral repair for CAD/CAM indirect restoration, adequate and stable adhesion of the repair materials is needed to both tooth substrate, such as enamel and dentin, and restored material. Moreover, the intraoral use of hydrofluoric acid should be omitted [4]. APP treatment might promote improved adhesion of repair material to enamel/dentin surface, due to enhance the surface energy of adhered tooth substrate [37-39]. In our previous and present studies, however, neither APP nor UV could improve the bond strength between a repair material (resin composite) and ceramic-based CAD/CAM indirect restorative materials [40]. Other researchers also reported that plasma treatment did not promote adhesion to PEEK (polyetheretherketone) or titanium [27,41]. Additionally, prolonged exposure to UV light has well known adverse health effects, especially ocular damage [42]. Therefore, 
the application of plasma or UV for repairing of indirect CAD/CAM dental restoration should not be recommended.

\section{Conclusions}

Based on the present findings, it can be concluded that (1) application of a silane coupling agent after phosphoric acid treatment enhanced the water CA of a leucite-reinforced glass ceramic surface; (2) application of a silane coupling agent after phosphoric acid treatment increased the repair bond strength of a resin composite with the leucite-reinforced CAD/CAM ceramic block; and (3) pre-treating the CAD/CAM glass ceramic with atmospheric-pressure plasma or UV light did not improve the repair bond strength.

Author Contributions: Conceptualization, A.K.; Methodology, A.K. and M.Y.; Software, A.T. and M.Y.; Validation, T.T., M.F. and S.Y.; Formal Analysis, A.K. and A.H.; Investigation, A.K., A.H., A.T. and A.N.; Resources, A.K. and A.H.; Data Curation, A.K.; Writing-Original Draft Preparation, A.K.; Writing-Review \& Editing, A.H., A.T., A.N., T.T., M.Y., M.F. and S.Y.; Visualization, A.K., M.Y.; Supervision, S.Y.; Project Administration, A.K.; Funding Acquisition, A.K. and A.H.

Funding: This work was partially supported by JSPS KAKENHI Grant Numbers JP 17K11715 and JP 16K20464.

Acknowledgments: We thank Melissa Gibbons, from Edanz Group (www.edanzediting.com/ac) for editing a draft of this manuscript.

Conflicts of Interest: The authors declare no conflict of interest.

\section{References}

1. Stawarczyk, B.; Sener, B.; Trottmann, A.; Roos, M.; Özcan, M.; Hämmerle, C.H.F. Discoloration of manually fabricated resins and industrially fabricated CAD/CAM blocks versus glass-ceramic: Effect of storage media, duration, and subsequent polishing. Dent. Mater. J. 2012, 31, 377-383. [CrossRef] [PubMed]

2. Sugiyama, T.; Kameyama, A.; Enokuchi, T.; Haruyama, A.; Chiba, A.; Sugiyama, S.; Hosaka, M.; Takahashi, T. Effect of professional dental prophylaxis on the surface gloss and roughness of CAD/CAM restorative materials. J. Clin. Exp. Dent. 2017, 9, e772-e778. [CrossRef] [PubMed]

3. Heintze, S.D.; Rousson, V. Fracture rates of IPS Empress all-ceramic crowns-A systematic review. Int. J. Prosthodont. 2010, 23, 129-133. [PubMed]

4. Loomans, B.A.C.; Mesco, M.E.; Roraes, R.R.; Ruben, J.; Bronkhorst, E.M.; Pereira-Centi, T.; Huysmans, M.C.D.N.J.M. Effect of different surface treatment techniques on the repair strength of indirect composites. J. Dent. 2017, 59, 18-25. [CrossRef] [PubMed]

5. Fabianelli, A.; Pollington, S.; Papacchini, F.; Goracci, C.; Cantoro, A.; Ferrari, M.; van Noort, R. The effect of different surface treatments on bond strength between leucite reinforced feldspathic ceramic and composite resin. J. Dent. 2010, 38, 39-43. [CrossRef] [PubMed]

6. Peumans, M.; Valjakova, E.B.; De Munck, J.; Mishevska, C.B.; Van Meerbeek, B. Bonding effectiveness of luting composites to different CAD/CAM materials. J. Adhes. Dent. 2016, 18, 289-302. [CrossRef] [PubMed]

7. Saracoglu, A.; Özcan, M.; Kumbuloglu, O.; Turkun, M. Adhesion of resin composite to hydrofluoric acid-exposed enamel and dentin in repair protocols. Oper. Dent. 2011, 36, 545-553. [CrossRef] [PubMed]

8. Loomans, B.A.C.; Mine, A.; Roeters, F.J.M.; Opdam, N.J.M.; De Munck, J.; Huysmans, M.C.D.N.J.M.; Van Meerbeek, B. Hydrofluoric acid on dentin should be avoided. Dent. Mater. 2010, 26, 643-649. [CrossRef] [PubMed]

9. Özcan, M.; Allahbeickaraghi, A.; Dündar, M. Possible hazardous effects of hydrofluoric acid and recommendations for treatment approach: A review. Clin. Oral Investig. 2012, 16, 15-23. [CrossRef] [PubMed]

10. Hagiwara, Y. Die strafrechtliche Verantwortung des Zahnarztes. Chuo Gakuin Univ. Rev. Fac. Law 2013, 26, 75-112. (In Japanese)

11. Watanabe, H.; Saito, K.; Kokubun, K.; Sasaki, H.; Yoshinari, M. Change in surface properties of zirconia and initial attachment of osteoblast like cells with hydrophilic treatment. Dent. Mater. J. 2012, 31, 806-814. [CrossRef] [PubMed] 
12. Noro, A.; Kaneko, M.; Murata, I.; Yoshinari, M. Influence of surface topography and surface physicochemistry on wettability of zirconia (tetragonal zirconia polycrystal). J. Biomed. Mater. Res. B Appl. Biomater. 2013, 101, 355-363. [CrossRef] [PubMed]

13. Kameyama, A.; Haruyama, A.; Asami, M.; Takahashi, T. Effect of emitted wavelength and light guide type on irradiance discrepancies in hand-held dental curing radiometers. Sci. World J. 2013, 2013, 647941. [CrossRef] [PubMed]

14. Mine, A.; De Munck, J.; Cardoso, M.V.; Van Landuyt, K.L.; Poitevin, A.; Kuboki, T.; Yoshida, Y.; Suzuki, K.; Lambrechts, P.; Van Meerbeek, B. Bonding effectiveness of two contemporary self-etch adhesives to enamel and dentin. J. Dent. 2009, 37, 872-883. [CrossRef] [PubMed]

15. Kameyama, A.; Bonroy, K.; Elsen, C.; Lührs, A.-K.; Suyama, Y.; Peumans, M.; Van Meerbeek, B.; De Munck, J. Luting of CAD/CAM ceramic inlays: Direct composite versus dual-cure luting cement. BioMed. Mater. Eng. 2015, 25, 279-288. [CrossRef] [PubMed]

16. Chang, J.C.; Hart, D.A.; Estey, A.W.; Chan, J.T. Tensile bond strengths of five luting agents to two CAD-CAM restorative materials and enamel. J. Prosthet. Dent. 2003, 90, 18-23. [CrossRef]

17. Van Landuyt, K.L.; De Munck, J.; Mine, A.; Cardoso, M.V.; Peumans, M.; Van Meerbeek, B. Filler debonding \& subhybrid-layer failures in self-etch adhesives. J. Dent. Res. 2010, 89, 1045-1050. [CrossRef] [PubMed]

18. Inoue, S.; Koshiro, K.; Yoshida, Y.; De Munck, J.; Nagakane, K.; Suzuki, K.; Sano, H.; Van Meerbeek, B. Hydrolytic stability of self-etch adhesives bonded to dentin. J. Dent. Res. 2005, 84, 1160-1164. [CrossRef] [PubMed]

19. Van Meerbeek, B.; Yoshihara, K.; Yoshida, Y.; Mine, A.; De Munck, J.; Van Landuyt, K.L. State of the art of self-etch adhesives. Dent. Mater. 2011, 27, 17-28. [CrossRef] [PubMed]

20. Cadenaro, M.; Antonialli, F.; Sauro, S.; Tay, F.R.; Di Lenarda, R.; Prati, C.; Biasotto, M.; Contardo, L.; Breschi, L. Degree of conversion and permeability of dental adhesives. Eur. J. Oral Sci. 2005, 113, 525-530. [CrossRef] [PubMed]

21. Kameyama, A.; Kato, J.; Yoshinari, M.; Kotoku, Y.; Akashi, G.; Hirai, Y. Ultimate micro-tensile strength of dental adhesives cured at different light source. J. Photopolym. Sci. Technol. 2008, 21, 31-35. [CrossRef]

22. Kameyama, A.; Kato, J.; De Munck, J.; Hatayama, H.; Haruyama, A.; Takase, Y.; Van Meerbeek, B.; Yoshinari, M.; Tsunoda, M. Light-curing efficiency of dental adhesives by gallium nitride violet-laser diode determined in terms of ultimate micro-tensile strength. BioMed. Mater. Eng. 2011, 21, 347-356. [CrossRef] [PubMed]

23. Yavuz, T.; Eraslan, O. The effect of silane applied to glass ceramics on surface structure and bonding strength at different temperatures. J. Adv. Prosthodont. 2016, 8, 75-84. [CrossRef] [PubMed]

24. Sattabanasuk, V.; Charnchairerk, P.; Punsukumtana, L.; Burrow, M.F. Effects of mechanical and chemical surface treatments on the resin-glass ceramic adhesion properties. J. Investig. Clin. Dent. 2017, 8, e12220. [CrossRef] [PubMed]

25. Lise, D.P.; Van Ende, A.; De Munck, J.; Vieira, L.C.C.; Baratieri, L.N.; Van Meerbeek, B. Microtensile bond strength of composite cement to novel CAD/CAM materials as a function of surface treatment and aging. Oper. Dent. 2017, 42, 73-81. [CrossRef] [PubMed]

26. Neis, C.A.; Albuquerque, N.L.; Albuquerque Ide, S.; Gomes, E.A.; Souza-Filho, C.B.; Feitosa, V.P.; Spazzin, A.O.; Bacchi, A. Surface treatments for repair of feldspathic, leucite- and lithium disilicate-reinforced glass ceramics using composite resin. Braz. Dent. J. 2015, 26, 152-155. [CrossRef] [PubMed]

27. Stawarczyk, B.; Bähr, N.; Beuer, F.; Wimmer, T.; Eichberger, M.; Gernet, W.; Jahn, D.; Schmidlin, P.R. Influence of plasma pretreatment on shear bond strength of self-adhesive resin cements to polyetheretherketone. Clin. Oral Investig. 2014, 18, 163-170. [CrossRef] [PubMed]

28. Soderholm, K.J.; Shang, S.W. Molecular orientation of silane at the surface of colloidal silica. J. Dent. Res. 1993, 72, 1050-1054. [CrossRef] [PubMed]

29. Yoshihara, K.; Nagaoka, N.; Sonoda, A.; Maruo, Y.; Makita, Y.; Okihara, T.; Irie, M.; Yoshida, Y.; Van Meerbeek, B. Effectiveness and stability of silane coupling agent incorporated in 'universal' adhesives. Dent. Mater. 2016, 32, 1218-1225. [CrossRef] [PubMed]

30. Tendero, C.; Tixier, C.; Tristant, P.; Desmaison, J.; Leprince, P. Atmospheric pressure plasmas: A review. Spectrochim. Acta Part B 2006, 61, 2-30. [CrossRef]

31. Liu, Y.; Liu, Q.; Yu, Q.S.; Wang, Y. Nonthermal atmospheric plasmas in dental restoration. J. Dent. Res. 2016, 95, 496-505. [CrossRef] [PubMed] 
32. Valverde, G.B.; Coelho, P.G.; Janal, M.N.; Lorenzoni, F.C.; Carvalho, R.M.; Thompson, V.P.; Weltemann, K.D.; Silva, N.R. Surface characterisation and bonding of Y-TZP following non-thermal plasma treatment. J. Dent. 2013, 41, 51-59. [CrossRef] [PubMed]

33. Ito, Y.; Okawa, T.; Fukumoto, T.; Tsurumi, A.; Tatsuta, M.; Fujii, T.; Tanaka, J.; Tanaka, M. Influence of atmospheric pressure low-temperature plasma treatment on the shear bond strength between zirconia and resin cement. J. Prosthodont. Res. 2016, 60, 289-293. [CrossRef] [PubMed]

34. Park, C.; Yoo, S.-H.; Park, S.-W.; Yun, K.-D.; Ji, M.-K.; Shin, J.-H.; Lim, H.-P. The effect of plasma on shear bond strength between resin cement and colored zirconia. J. Adv. Prosthodont. 2017, 9, 118-123. [CrossRef] [PubMed]

35. Han, G.-J.; Chung, S.-N.; Chun, B.-H.; Kim, C.-K.; Oh, K.-H.; Cho, B.-H. Effect of applied power of atmospheric pressure plasma on the adhesion of composite resin to dental ceramic. J. Adhes. Dent. 2012, 14, 461-469. [CrossRef] [PubMed]

36. Lee, M.-H.; Min, B.K.; Son, J.S.; Kwon, T.-Y. Influence of different post-plasma treatment storage conditions on the shear bond strength of veneering porcelain to zirconia. Materials 2016, 9, 43. [CrossRef] [PubMed]

37. Teixeira, H.S.; Coelho, P.G.; Duarte, S.; Janal, M.N.; Silva, N.; Thompson, V.P. Influence of atmospheric pressure plasma treatment on mechanical proprieties of enamel and sealant bond strength. J. Biomed. Mater. Res. B Appl. Biomater. 2015, 103, 1082-1091. [CrossRef] [PubMed]

38. Han, G.-J.; Kim, J.-H.; Chung, S.-N.; Chun, B.-H.; Kim, C.-K.; Seo, D.-G.; Son, H.-H.; Cho, B.-H. Effects of non-thermal atmospheric pressure pulsed plasma on the adhesion and durability of resin composite to dentin. Eur. J. Oral Sci. 2014, 122, 417-423. [CrossRef] [PubMed]

39. Hirata, R.; Teixeira, H.; Ayres, A.P.; Machado, L.S.; Coelho, P.G.; Thompson, V.P.; Giannini, M. Long-term adhesion study of self-etching systems to plasma-treated dentin. J. Adhes. Dent. 2015, 17, 227-233. [CrossRef] [PubMed]

40. Noro, A.; Kameyama, A.; Haruyama, A.; Takahashi, T. Influence of hydrophilic pre-treatment on resin bonding to zirconia ceramics. Bull. Tokyo Dent. Coll. 2015, 56, 33-39. [CrossRef] [PubMed]

41. Seker, E.; Kilicarslan, M.A.; Deniz, S.T.; Mumcu, E.; Ozkan, P. Effect of atmospheric plasma versus conventional surface treatments on the adhesion capability between self-adhesive resin cement and titanium surface. J. Adv. Prosthodont. 2015, 7, 249-256. [CrossRef] [PubMed]

42. Price, R.B.; Labrie, D.; Bruzell, E.M.; Sliney, D.H.; Strassler, H.E. The dental curing light: A potential health risk. J. Occup. Environ. Hyg. 2016, 13, 639-646. [CrossRef] [PubMed] 